\title{
Exploring the Impact of Professional Development Intervention through Reflection
}

\author{
Bahar Gün (Corresponding Author) \\ School of Foreign Languages, İzmir University of Economics \\ Sakarya Cad. No:156 35330 Balçova/İzmir Turkey \\ Tel: 90-232-4888358Ｅ-mail: bahar.gun@ieu.edu.tr
}

Received: January 18, 2017

Accepted: March 30, 2017

Published: July 29, 2017

doi:10.5296/jet.v4i2.10617

URL: http://dx.doi.org/10.5296/jet.v4i2.10617

\begin{abstract}
Rather than being an analytical research inquiry, this article presents assessment of a specific professional development intervention focusing mainly on the impact of a 3-month in-service teacher education program on 10 English language teachers in Turkey. The data comes from various sources, namely, surveys, interviews, classroom observations and reflective journal entries. The training program is described in three phases: pre-intervention, intervention and post-intervention. Based on the data collected during three phases, the training program can be claimed to have an obvious impact on not only the participant teachers' mind-sets about teaching but also on their day-to-day classroom practices.
\end{abstract}

Key words: professional development, intervention, reflection, impact

\section{Introduction}

It is agreed that teachers need constant training and development in order to maintain long-term achievement (Richards \& Farrell, 2005). One central component for any attempt to improve education is high-quality professional development (Guskey, 2002). Each and every teacher education program aims at bringing about change in classroom practices of teachers by motivating them to become better teachers. However, it is not always easily attainable to offer an effective professional development (PD) program because of the drawbacks listed by Borg (2015:13):

\begin{tabular}{cc}
\hline Infrequent & Teachers attend courses intermittently. \\
Costly & Teachers must pay to attend. \\
Disruptive & Teachers may be taken away from lessons \\
Generic & May not address individual needs of teachers and learners \\
Decontextualized & Learning is not situated in classrooms \\
Receptive & Knowledge is given to teacher by experts \\
Not-owned & Teachers have limited say in the process of training \\
\hline
\end{tabular}


Considering all these drawbacks, it is also recognized that teacher change is a gradual and challenging process, yet, sustaining change is even more challenging. To create a change, the teachers are usually presented a palette of training activities presented by different teacher educators, however, how much of the gain, if any, from them is actually taken on board and reflected in teachers' classroom teaching performances remains as a question mark. The role of the teacher educator, at this point, plays a vital role in the effectiveness of a program. As noted in O'Dwyer and Atl (2014) a teacher educator should be able to work with teachers "in a real institutional context, the classroom and with affective bonds" (p.12) to be able to create a permanent change. Lino (2014) agrees with them by asserting that teacher educators offering the PD programs should be familiar with the work context of the participant teachers.

Besides the importance of the quality of the teacher educator, including 'reflective practice' in any given PD program is equally vital. A reflective approach to teaching is one in which teachers collect data about teaching, examine their attitudes, beliefs, assumptions and teaching practices, and use of information obtained as a basis for critical reflection about teaching (Richards and Lockhart, 1994).

If teachers are equipped with reflective skills, namely, if they are able to confront their own routine practice, then the impact of the program is inevitably more effective. Reflective teachers can "determine the specific areas of their teaching that they wish to develop, and formulate their own agenda for change in the classroom" (Lamb, 1995: 79).

\subsection{Impact of Training Programs}

As suggested by Borg (2011) there has been surprisingly little research into the extent to which teacher education, particularly in in-service context, does actually impact in some way on the beliefs of participating teachers" (p:370). Most of the research conducted in the field of teacher education focuses mostly on the procedures of the education programs employed, somewhat neglecting the "real" impact on teachers' daily practices. If we are interested in studying the impact of teacher education, then there comes the question about how to measure and make legitimate claims about this impact. There are some studies that question the effectiveness of the teacher education programs to the issues related to the measurability of the impact (Knight, 2002; Kwakman, 2002; Cochran-Smith, 2001). Breault (2010) also criticizes the studies on professional development of teachers at schools by suggesting they merely tell success stories "with little or no attempt at critical reflection, analysis or interpretation or provide a thorough description of PD activities" (p.399).

Any attempt to understand the impact of teacher education means to be able to understand the processes which shape teachers' teaching behavior; and this encompasses understanding the complexities of their thinking, and the link between their beliefs, their thinking and their actual classroom practice (Phipps, 2007). Even if teachers' beliefs can be changed through some effective teacher education program, there is no guarantee that this will be translated into a change in actual teaching (Richardson, 1996). Cochran-Smith (2000) identifies three major ways that the outcomes question in teacher education is being constructed in the research literature, the policy arena, and the media: outcomes as long term impact, outcomes 
as teacher test scores, and outcomes as professional performance. The current study mainly focuses on the outcomes as professional performance as a result of a PD intervention.

\section{Study}

\subsection{Aim of the study}

The concept of "impact" being the core, this study mainly aims to identify evidence of teacher learning resulting from a given PD program which focuses on improving teaching and teachers' reflective skills.

\subsection{Participants}

The participants of the study were 10 Turkish (non-native speakers) English language teachers ( 3 females-7 males) at a military vocational school in Turkey. Their experience ranged between 6 months to 17 years; and the age range was 26 to 37 . They taught general English to a group of cadets in an intensive program. An in-service teacher education program for professional development ws provided at the participants' request, and the participants themselves initiated contact with the researcher. They had made themselves familiar with the RTL program by reading about the author's previous work on reflective practice (Author, 2011, 2015). The main premise of the RTL program is that although teachers are encouraged to reflect on their teaching, they may not do it effectively and they need specific training to be able to reflect critically. The teachers involved in this program are offered opportunities to observe themselves teaching to identify their weaknesses and strengths, to share their experience of teaching, and learn through focused discussions with colleagues and trainers and to become autonomous by finding alternative approaches to development.

\subsection{Methodology}

The training program was conducted in three phases: pre-intervention, intervention, and post-intervention. In such studies, impact is often measured through questionnaires, interviews, observations and journal writing (Borg, 2006). Due to the complexity of the teacher learning process, relying on a single instrument would not be sufficient; therefore, the following were used to collect data in the current study:

- Surveys

- Observations

- $\quad$ Reflective Journal Entries

- $\quad$ TLAP (Teacher Learning Action Plan) documents

\section{Pre-Intervention Phase}

This phase aimed to gauge the teachers' understanding of Reflective Teaching and Learning (RTL) as well as their expectations from the PD program to be delivered to them.

Below you can see the randomly selected quotations from the teachers' written answers to the 
question: "What do you know about RTL?"

Teacher A (TA): "I've always wanted to observe my colleagues. I've always believed in RTL but I don't know how to do it professionally"

TF: "It's the reflection of an instructor during classes in terms of teaching style, activities and student learning process. It's a mirror. We can see the missing parts of the puzzle".

TG: "my understanding of RTL is to be aware of what we are doing. Are we teaching indeed? Or do we suppose so? Yes, we suppose so."

Considering the fact that the teachers approached the researcher specifically for an RTL training, it is obvious from the quotes above that they had an idea about what RTL roughly is and what it entails; but they wanted to learn more about it, especially how to put it into practice.

When their expectations from the program were asked, the participant teachers said:

TA: "This is the opportunity I have been looking for since the beginning of my career". I am going to learn my strengths and weaknesses and have the chance to improve my teaching skills".

TB: "To realize what is 'really' going on in the classroom”.

TC: "It will help me get to know myself better which might bring more peace and joy to both my personal and professional life".

TG: "To be able to criticize myself and correct my mistakes and provide better teaching and learning. Nobody will have to question my job. I will be the "wanted" teacher.

It can be concluded from the quotes above that the teachers in this study came together in order to become more confident and reflective teachers.

\subsection{Video Task}

Prior to the RTL training program, one other activity that was given to the teachers in the pre-intervention phase was to get them to watch a teaching video and complete a small task, namely, to write down their impressions about the lesson they viewed and to write down the lesson objective.

The impressions noted down by the teachers were mostly about how the students looked and how the teacher looked and the teacher's attitude:

"She looks serious"

"She looks bossy"

"Students are bored"

"She is polite and friendly"

"Messy board" etc. 
Regarding the objective of the lesson viewed, only 4 out of 10 teachers identified the lesson objective correctly which was writing a compare-contrast paragraph. Here are some quotes from the teachers' written notes:

\section{"As I guess she is trying to give the students the courage they need to speak"}

"I think it was a content based teaching of English"

"I'm not sure what the aim is"

"To present different forms of words; noun, verb, etc."

In summary, in the pre-intervention phase it was clear that the participant teachers did not have a clear idea of what exactly RTL was and they had issues identifying the main lesson objectives, and that they were willing and enthusiastic about becoming more reflective practitioners, therefore, more effective teachers.

\section{Intervention Phase}

Having established the teachers' prior level of reflection on their practices in the pre-intervention phase, the intervention phase of the program was mainly consisted of input sessions and classroom observations conducted based on the observation tasks designed for different aspects of classroom teaching (Gün, 2011), namely, Lesson Objectives, Teacher Talking Time (TTT), Instructions, Error Correction and Feedback.

In the very first input session, the definition and description of 'Reflective Practice' were explored through group discussions based on the readings that had been assigned by the trainer at the outset. This session aimed at making the aim of 'Reflective Teaching and Learning' clear to all the participants, and how it could help them contribute to their professional development regardless of the years of teaching experience they had.

In the consecutive sessions, the observation tasks were set and each session mainly focused on the reflections of the observed teachers after they watched their video recorded lessons as well as the formal presentations of the trainer regarding the focused aspects of classroom teaching. All these sessions were carried out in an amiable atmosphere in which the teachers felt comfortable with reflecting on their own experiences as well as interacting with one another through commentating.

As noted by Richards and Farrell (2005), language teachers get together in groups on the basic assumption that collaborating with a group of colleagues will be more effective than reflecting alone, and the reflective conversations formed in the input sessions in this study were the prime examples of these effective exchanges.

\subsection{Journal Entries}

Throughout the intervention phase, the participant teachers were asked to keep reflective journals in which they noted down their impressions and feelings about the input sessions as well as their classroom observations. Reflective Journal analysis, as McDonough (1994) suggests helps us see what kind of issues teachers are preoccupied by, and how they perceive 
things" (p.57). In that sense, journal keeping proved to be very useful for probing the teachers' minds.

What follows are the randomly selected quotations compiled from the teachers' reflective journals throughout the intervention phase:

TD : "I've always thought that I am doing enough, but I see that I'm wrong. I've lots to learn".

TF: "I noticed I should focus on my attitude and my expectations more".

TB: "I've already started reflecting".

TG: "I realized that I am always at the center in my lessons, I talk a lot, students seemed to be active but they didn't even ask one single question. We had only fun in class. There was almost no learning. I have to change some things, I think".

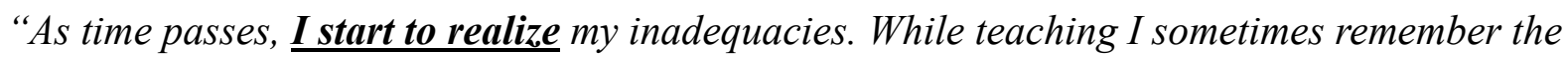
questions we discuss in our sessions: What did they learn today? What did I learn today?"

“I realize I can't overcome echoing, repeating myself and completing my students' sentences. I have to try harder, I think"

"I realize I don't give enough feedback to my students. I don't know why but when everything seems good I don't feel obliged to give positive feedback, but now I see that it is a must. I will try it for the next lesson."

TC: "In today's session I remembered that that are many ways of correcting errors".

TA: "After today's session I will pay more attention while correcting errors and use different strategies like finger correction".

TE: "In my lesson today, I reminded myself the 'wait-time' and I waited longer than usual. As a result, students gave the answer. Normally, I would just correct or give the answer myself-without waiting".

As evident in the quotes above, the teachers' level of reflection increased in the course of the training program. The teachers were able to identify and reflect upon critical incidents in their lessons thanks to the reflective discussions that took place during the input sessions alongside with focused observations. These quotes also specifically show that the teachers were able to identify the gaps in their knowledge, skills and attitude that hindered more effective teaching practices. The use of the verbs like "realize", "see" and "notice" are also indicators of increasing awareness.

\section{Post-Intervention Phase}

\subsection{Survey}

This particular phase aimed at allowing evaluation of the teachers' ability to come up with action plans as a result of their reflections on their performance as language teachers. To this aim, the teachers were given a mini survey including the following questions 
1- How do you think you have changed so far?

2- How are you planning to change in the future?

What follow are the quotes from the teachers' responses to these two questions:

TI: "Before RTL I didn't do much prep for my classes, but now I am spending more time to prepare than the time spent on teaching"

TD: "Before this course, I used to think I was doing well, and that gave me unnecessary confidence, but now I can see that there are still lots more to learn".

TD: "In the future, I'm planning to record a few more videos of my classes and watch them over and over again. Maybe I can interview my students to see how they feel in my lessons".

TJ: "RTL training has surely given me insights into how I should give my instructions and what options I can use when I correct errors".

TJ: "I am planning to focus more on reducing my TTT and presenting lesson aims clear enough for the students"

TH: "In every lesson, I am trying to reduce my TTT, asking good ICQs, not just "Do/Did you understand?", and I am trying to use different error correction techniques effectively."

TA: "RTL training has made a big change in my teaching style. I realized I need to focus on 'learning' more than 'teaching' in my classes. I now prepare more for my classes, and I realize that I don't need to cover everything in the book. I feel like I am doing something really useful for my career".

TG: "RTL has raised my awareness for sure. While I teach I think twice now. I try to talk less. I'm conscious now. I'm changed"

TG: "I am planning to be more silent. I will let my students talk. $\underline{I}$ will try to give clear instructions and only when necessary I will correct the mistakes".

TF: "I noticed that I didn't focus on learning as much as I should have. Self-awareness and enlightenment are the key words for me in this process."

As can be seen in the quotes above, both the teachers' 'reflection-on-action" and "reflection-for action" skills have been tapped with the given two questions. Namely, the teachers mentioned both the changes they have already gone through and their plans for the future-as highlighted in the quotations. Based on these answers it can be concluded that the participant teachers' awareness about their teaching performance was clearly raised in the course of the given training program.

\subsection{TLAP (Teacher Learning Action Plan)}

Having been given the survey, the teachers in the study were also introduced to the Kolb's Experiential Learning Cycle (Kolb, 1983 in Randall \&Thornton, 2001:45), which is one of the most powerful models of learning which explains how people learn from experience: 


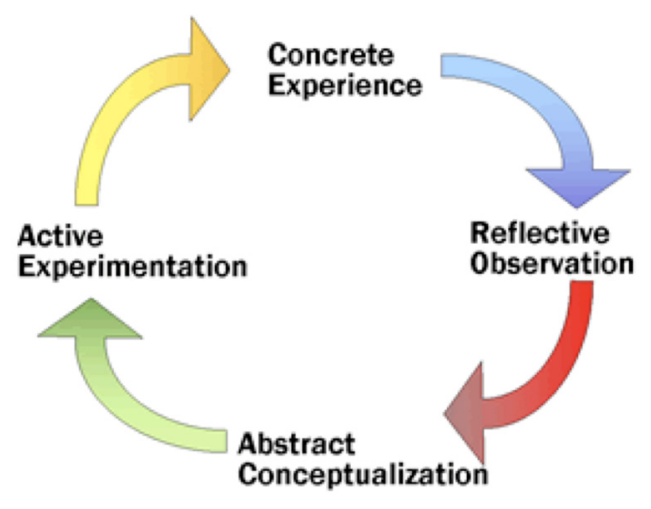

The explanation of the cycle and making its premise clear to the teachers was followed up by a series of questions which eventually led to TLAP: Teacher Learning Action Plan:

1. What is the issue/ curiosity/ inquiry/ concern you have?

2. Why is it important to the learning of your students?

3. Where will this issue/ curiosity/ inquiry/ concern be examined?

4. How will this issue/ curiosity/ inquiry/ concern be investigated?

5. How will I know the goal has been achieved and if the students have learned? What will success look like?

6. Summarize your focus keeping learning in mind.

Through these questions, the teachers were mainly asked to identify an area to work on based on their current reflections. Having answered the questions the teachers were invite to share their answers in a whole-group reflective discussion format.

\subsection{Reflective Discussions}

This particular post-course reflective discussion session aimed at sharing the action plans the teachers came up with after answering the six TLAP questions. In this interactively conducted session, it was seen that 8 out of 10 teachers identified Teacher Talking Time (TTT) as an area for improvement. The reasons stated by the teachers as to why they thought their TTT was very high were:

- their instructions were not clear enough

- their questions were not clear enough

- they didn't tolarate silence, and

- they were echoing and/or repeating themselves

It was rather interesting and impressive to watch the teachers converse about their weaknesses and their underlying reasons thanks to the reflective skills they appeared to have developed throughout the training programme. 


\subsection{Video task (repeated)}

The next post-course task the teachers needed to complete was to repeat the same video activity they had done in the pre-course phase. They watched the same video and wrote down their impressions about the lesson, and this was followed a whole group discussion. It was rather obvious that their impressions changed immensely. They now made many sensible comments about error correction, TTT, feedback and the teacher's instructions in the video. To get them to realize how much they changed over time, they were given the pre-course tasks that had been collected by the researcher at the beginning of the study. Having compared their two task sheets, the teachers came to realize how much more "aware" they had become in the given training programme.

\subsection{Post course observations}

The same type of changes and much raised awareness were also evident in the post-course classroom observations carried out by the researcher. The teachers in that phase delivered, more student-centered and more 'learning-oriented' lessons in a much more confident manner by paying particular attention to the aspects of classroom teaching that were tackled in the program.

\subsection{End of course feedback}

In the final session of the post-course phase, the teachers were invited to provide feedback about the usefulness of the entire training program by answering some open ended questions and completing the questionnaire in the Appendix.

A close analysis of teachers' responses to the open ended questions indicate that the most repeated word in all the feedback forms was "awareness". The teachers stated that they surely felt much more confident now particularly about the 5 areas focused in the program. They also noted that they better grasped the importance of "learning-centredness" at the end of this training. The common adjectives they used about their lessons during and after the training were "inspiring", "joyful" and "effective".

Regarding their further development, they expressed their desire to video record more of their lessons and reflect on them by making comparisons about their teaching styles and techniques. They also asked for the researcher's help and support by watching their teaching more and giving them feedback about not only for the five aspects covered in the training but the other aspects of classroom teaching that were not explicitly tackled in the 3-month program.

A striking anectode on the feedback form written by one of the participant teachers is well worth noting here since it gives a very clear indication of the impact of the PD intervention focused in this study:

In one of my lessons, a student in the class said to me "something came over you.... we have been having the most enjoyable and effective lessons ever in the last few weeks". This comment made me pleasantly surprised about how much I must have changed in the RTL training program. 
As for the results of the questionnaire in which. 5 Liket Scale was used, the avarage was 4.3. The area many teachers were undecided about was "grading the language", which looks like an area for futher development about their teaching; and the points they disagreed were their ability to be able to "think on their feet" and making sure "enough learning was taking place in their lessons". They clearly needed more reflection about these points to further improve their teaching.

Overall, based on all the feedback collected in the post-course phase; it would be fair to say that the positive impact of the given PD intervention program was evident.

\section{Conclusion}

As a result, it would be fair to say the PD intervention program offered to 10 English teachers was overall a successful one because there was clear evidence that the RTL course had considerable impact on the beliefs and practices of the participant teachers. There were quiet a few tangible changes in teachers' classroom practices. The success of the program could be attributed to the following:

1) The limitations listed by Borg (2015) were largely eliminated in the current study. Namely, the program offered was not "infrequent, costly, disruptive, generic, decontextualized, receptive and not-owned" (p.13)

2) There was a wide variety of tools used to measure the impact of the training program: reflective journals, classroom observations, reflective tasks and discussions, surveys and feedback forms

3) The key factors which stimulated the teachers' learning during the program were the reflective tasks they needed to complete, individual support and guidance provided by the trainer, keeping a journal, and having to come up with an action plan.

Through such training, teachers' beliefs can be strengthened and extended; teachers translate their beliefs into practice (Borg, 2011; Phipps, 2007). It was seen in this study that the teachers were somewhat able to identify their weaknesses but the comment "I don't know what to do" was rather frequent both in their reflective journals as well as the reflective group discussions. This suggests an obvious need for guidance and support.

This study also confirmed the value of Reflective Conversations/Discussions (Richards and Farrell, 2005) in the sense that as a result of participating in teacher development groups teachers can change their thinking about their work and can become more confident language teachers. Therefore, it should always be considered that teachers work in a social context, the knowledge they construct is not done in a vacuum, but constructed within a classroom (contextually), and with learners and teachers (socially) (Roberts, 1998).

Another significant conclusion that can be drawn from the study relates to the types of reflection Schön (1983, 1987 in Farrell, 2012) mentions: Reflection in and on action can encourage teachers to reflect 'for' action. The participant teachers in the study clearly exercised both reflection in and on action, which subsequently led them to come up with realistic action plans for their further improvement as effective teachers (reflection-for-action). 
It is hoped that the insights gained from this study adds to the existing knowledge about the impact of teacher education programs in the literature.

\section{Implications}

As emphasized by Borg (2011), studies focusing on the 'impact' of training programs are needed to provide stronger evidence of the links between the course and teachers' subsequent professional practices. This study implies that while designing an effective teacher education program the following factors should be focused on:

1) Reflection training should be incorporated in the program as it enables teachers to understand why they are being encouraged to examine their beliefs. It was clear in the present study that the teachers were not able to criticically reflect at the outset of the study, however, they sharpened their reflective skills towards the end of the training program (Author, 2011).

2) Reflective Conversations should definitely have a role to play for any training program as they contribute to enhancing the teachers' professional development (Ashraf \& Rarieya, 2008), by trigerring their awareness about their beliefs and practices in teaching.

3) Teacher Education programs should see the teacher as knowledge creator (Borg, 2015 b). One of the contributing factors to the success of the training program in this study was the way the teachers were seen as capable of creating knowledge about effective teaching rather than merely receiving it from a trainer.

4) Teacher Education programs should be offered in the same context as the teacher would normally teach, development should not be a separate entity from teaching (McLaughlin \& Zarrow, 2001), which was one of the strengths of the present study.

5) Trainings of this kind should not be divorced from classroom practice. It was a huge advantage for the participant teachers to be able to go into their classes and try out the things they learnt from the input sessions as well as their own reflections.

6) Content should not be too broad. Programs attempting to cover as many areas of classroom teaching as possible would be too ambitious, and would end up overwhelming the participant teachers, hindering the possible positive impact of the training.

Even though the study at hand is limited in its scope and the findings cannot be generalised, it has shown that teacher education programs can prove to be useful as long as the trainers work more closely with individual teachers in their own context by getting them to be effective RTL practitioners to the best of their abilities. It is clear that examining teacher learning results and processes similar to the ones in this study will require more extensive research in order to produce knowledge needed to establish how teacher learning may contribute to reaching desired reform outcomes" (Kwakman, 2002, p.166).

In conclusion, it is worth noting that in designing effective teacher education programs the trainers should never lose sight of the fact that "significant, meaningful and long term positive change will be achieved only when it comes as a decision from within the individual....based on self-evaluation" (Lapp et al., 2002). 


\section{References}

Ashraf, H., \& Rarieya, J. F. A. (2008). Teacher development through reflective conversations-possibilities and tensions-Pakistan case. Reflective Practice: International and Multidisciplinary Perspectives, 9, 3, 269-279.

Borg, S. (2011). Teacher Learning on the Delta. Cambridge ESOL Research Notes, 45, 19-25.

Borg, S. (2011). The impact of in-service teacher education on language teachers' beliefs. System, 39, 370-380.

Borg, S. (2015a). Professional learning through teacher research. In D. Xerri, \& V. Odeete (Eds.), The learning ELT professional. Malta: ELT council.

Borg, S. (2015b). Beyond the workshops: CPD for English language teachers. In S. Borg. (Ed.), Professional development for English language teachers: Perspectives from higher education in Turkey. (pp. 5-12), Ankara: British Council.

Breault, R. A. (2010). Distilling wisdom from practice: Finding meaning in PDS stories. Teaching and Teacher Education, 26, 399-407.

Cochran-Smith, M. (2001). The outcomes question in teacher education. Teaching and Teacher Education, 17, 527-546.

Farrell, T. (2012). Reflecting on reflective practice: (Re) Visiting Dewey and Schön. TESOL Journal, 3(1), 7-16.

Gün, B. (2011). Quality Self-reflection through Reflection Training”. ELT Journal, 65(2), 126-135.

Gün, B. (2015). The reflective teaching and learning programme. In S. Borg (Ed.), Professional Development For English Language Teachers. British Council Publication, 65-73.

Guskey, R. T. (2002). Professional development and teacher change. Teachers and Teaching, $8(3), 381-391$.

Knight, P. (2002). A systemic approach to professional development: learning as practice. Teaching and Teacher Education, 18, 229-241.

Kwakman, K. (2003). Factors affecting teachers' participation in professional learning activities. Teaching and Teacher Education, 19, 149-170

Lamb, M. (1995). The consequences of INSET. ELT Journal, 49(1), 72-80.

Lapp, N., Lascher, T., Matthews, T., Papalewis, R., \& Stoner, M. (2002). A proposal for formative assessment of teaching. Retrieved March. 4, 2004, from http://home.sou.edu/ vidmar/reflective_peer_coaching/FormativeAssessmentLitReview. pdf 
Lino, D. (2014). Early childhood teacher education: How to enhance professional development. Journal Plus Education/Education Plus, 11(2), 200-209.

McDonough, J. (1994). A teacher looks at teachers' diaries. ELT Journal, 48(1), 57-65.

McLaughlin, M. W., \& Zarrow, J. (2001). Teachers engagement in evidence-based reform: Trajectories of teachers' inquiry, analysis, and action. In A. Lieberman \& L. Miller. (Eds.), Teachers Caught in the Action: Professional development that matters. (pp. 24-35) New York: Teachers College Press

O’Dwyer, J. B.,\& Atl1, H. (2014). A study of in-service teacher educator roles, with implications for a curriculum for their professional development. European Journal of Teacher Education, 38(1), 4-20.

Phipps, S. (2007). What difference does DELTA make? Cambridge ESOL Research Notes, 29, 12-16.

Randall, M., \&Thornton, B. (2001). Advising and Supporting Teachers. Cambridge: CUP.

Richards, J. C., \& Farell, T. S. C. (2005). Professional Development for Language Teachers. Cambridge: CUP

Richardson, V. (1996). The role of attitudes and beliefs in learning to teach. In B. T. Sikula, \& E. Guyton (Eds). Handbook of Research in Teacher Education. New York: MacMillan, 102-119.

Roberts, J. (1998). Language Teacher Education. London: Arnold, Hodder Headline Group.

Schön, D. A. (1983). The reflective practitioner: How professionals think in action. Basic Books.

\section{Copyright Disclaimer}

Copyright reserved by the author(s).

This article is an open-access article distributed under the terms and conditions of the Creative Commons Attribution license (http://creativecommons.org/licenses/by/3.0/). 